\title{
Protein Kinase C Mediates the Corticosterone- induced Sensitization of Dorsal Root Ganglion Neurons Innervating the Rat Stomach
}

\author{
Meng Li, Lu Xue, Hong-Yan Zhu, Hongjun Wang, Xue Xu, Ping-An Zhang, Geping Wu, and Guang-Yin Xu* \\ The Affiliated Zhangjiagan Hospital of Soochow University, Jiangsu Key Laboratory of Translational Research and Therapy for Neuro-Psycho- \\ Diseases, Institute of Neuroscience, Soochow University, Suzhou, China
}

\section{Background/Aims}

Gastric hypersensitivity contributes to abdominal pain in patients with functional dyspepsia. Recent studies showed that hormones induced by stress are correlated with visceral hypersensitivity. However, the precise mechanisms underlying gastric hypersensitivity remain largely unknown. The aim of the present study was designed to investigate the roles of corticosterone (CORT) on excitability of dorsal root ganglion (DRG) neurons innervating the stomach.

\section{Methods}

DRG neurons innervating the stomach were labeled by Dil injection into the stomach wall. Patch clamp recordings were employed to examine neural excitability and voltage-gated sodium channel currents. Electromyograph technique was used to determine the responses of neck muscles to gastric distension.

\section{Results}

Incubation of acutely isolated DRG neurons with CORT significantly depolarized action potential threshold and enhanced the number of action potentials induced by current stimulation of the neuron. Under voltage-clamp mode, incubation of CORT enhanced voltagegated sodium current density of the recorded neurons. Pre-incubation of GF109203X, an inhibitor of protein kinase C, blocked the CORT-induced hyperexcitability and potentiation of sodium currents. However, pre-incubation of $\mathrm{H}-89$, an inhibitor of protein kinase A, did not alter the sodium current density. More importantly, intraperitoneal injection of CORT produced gastric hypersensitivity of healthy rats, which was blocked by pre-administration of GF109203X but not H-89.

\section{Conclusions}

Our data strongly suggest that CORT rapidly enhanced neuronal excitability and sodium channel functions, which is most likely mediated by protein kinase $\mathrm{C}$ but not protein kinase $\mathrm{A}$ signaling pathway in DRG neurons innervating the stomach, thus underlying the gastric hypersensitivity induced by CORT injection.

(J Neurogastroenterol Motil 2017;23:464-476)

\section{Key Words}

Corticosterone; Ganglia, spinal; Protein kinase C; Visceral pain; Voltage-gated sodium channel

Received: September 21, 2016 Revised: December 31, 2016 Accepted: January 15, 2017

(.) This is an Open Access article distributed under the terms of the Creative Commons Attribution Non-Commercial License (http://creativecommons. org/licenses/by-nc/4.0) which permits unrestricted non-commercial use, distribution, and reproduction in any medium, provided the original work is properly cited.

${ }^{*}$ Correspondence: Guang-Yin Xu, MD, PhD Jiangsu Key Laboratory of Translational Research and Therapy for Neuro-Psycho-Diseases, Institute of Neuroscience, Soochow University, 199 Ren-Ai Road, Suzhou 215123, China

Tel: +86-512-6588-2817, Fax: +86-512-6588-3602, E-mail: guangyinxu@suda.edu.cn

Meng Li, Lu Xue, and Hong-Yan Zhu contribute to this work equally. 


\section{Introduction}

Functional dyspepsia (FD) affects $10-25 \%$ of the population according to various estimates. ${ }^{1,2}$ Its primary symptom is upper epigastric pain or discomfort in the absence of organic ailments. ${ }^{3,4}$ Although the pathogenesis of this heterogeneous disorder remain largely unknown, gastric hypersensitivity is thought to contribute to the abdominal pain in patients with FD. A growing body of evidence demonstrates that physical or mental distress alters gut immunity and modulates the processing of incoming sensory signals by the brain, thus leading to a potentiation of sensory signals and aberrant visceral pain perception. ${ }^{5-8}$ Corticosterone (CORT), one of the most important stress hormones, plays complex effects in neurological diseases. ${ }^{9,10} \mathrm{~A}$ recent report showed that neonatal colonic chemical irritation with acetic acid produced FD-like gastric hypersensitivity and that inhibition of glucocorticoid receptors (GRs) during neonatal insult suppressed gastric hypersensitivity in adult rats. ${ }^{7}$ In addition, chronic psychological stress increased CORT levels by activation of hypothalamic-pituitary-adrenal (HPA) axis, thus increasing the perception of visceral pain. ${ }^{11}$ These data strongly indicate that CORT induced by physical or/and psychological stress is involved in chronic visceral hypersensitivity. However, how CORT causes visceral hypersensitivity is not fully understood.

Once released from the adrenal glands in responding to stress, CORT quickly enters the brain and peripheral nerves system, and binds to intracellular receptors. ${ }^{5,12}$ One of the primary targets of the stress hormone is the dorsal root ganglion (DRG), a region that conveys and controls somatic and visceral sensation. ${ }^{11,13,14}$ Exogenous application of CORT $1 \mu \mathrm{M}$ overnight has been shown to enhance DRG neuronal excitability. ${ }^{15}$ The CORT-induced effect is because of its genomic effects through new protein synthesis. ${ }^{16}$ However, mounting evidence also shows that CORT may exert rapid effects on neurons through non-genomic pathways. CORT prolonged N-methyl-D-aspartate (NMDA)-induced $\mathrm{Ca}^{2+}$ elevation in cultured rat hippocampal neurons, ${ }^{17}$ indicating that CORT can rapidly modulate the function of NMDA receptors by non-genomic pathway. Another study shows that application of CORT for 1 hour significantly increased the density of spines of CA1 pyramidal neurons, which was abolished by co-administration of RU486, an antagonist of GRs. Blocking protein kinase $\mathrm{C}$ (PKC) or other single kinase, suppressed the CORT effects. ${ }^{18}$ These studies demonstrate the possible existence of fast-acting, non-genomic effects of CORT in neurons both functionally and structurally. Emerging evidence suggests that voltage-gated sodium channels (VGSCs) plays an important role in both stress and pain. ${ }^{19}$ Very recent studies indicated PKC activation leads to an increase in the membrane expression of VGSCs and facilitates sodium currents in cortical neurons, ${ }^{20,21}$ indicating that PKC may be involved in mediating VGSCs functions. However, whether and how CORT plays an acute effect on VGSCs of DRG neurons innervating the stomach is not clear.

In the light of the growing evidence, we therefore hypothesize that CORT sensitized the neuronal excitability and enhanced sodium channel activities via activation of PKC in gastric specific DRG neurons. The aim of this study was designed to explore the roles of CORT on the excitability and VGSC currents of DRG neurons innervating the stomach. In addition, the intracellular pathways mediating the CORT effects were also explored. This study might shed light on the pathogenesis of functional gastrointestinal disorders such as FD under acute or chronic conditions. ${ }^{22}$

\section{Materials and Methods}

\section{Animals}

All experiments were approved by the institutional animal care and use committee at Soochow University and by the Association of Laboratory Animals in Jiangsu Province, China. Adult male Sprague-Dawley rats (6 weeks) were housed four per cage under 12 hours/12 hours dark/light cycle and in a temperature-controlled room $\left(25 \pm 1^{\circ} \mathrm{C}\right)$. Animals were allowed to access the tap water and standard food.

\section{Dil Labeling of Dorsal Root Ganglion Neurons Innervating the Stomach}

The gastric project neurons were retrogradely labeled using 1,19-dioleyl-3,3,39,3-tetramethylindocarbocyanine methane sulfonate (DiI; Invitrogen, Carlsbad, California, USA) as described previously (Fig. 1A). ${ }^{23}$

\section{Whole-cell Patch-clamp Recordings}

Neuronal excitability was determined by whole-cell patchclamp recordings as described previously. ${ }^{23}$ In short, DRGs $\left(\mathrm{T}_{7^{-}}\right.$ $\mathrm{T}_{10}$ ) were acutely dissected out and incubated in dissecting solution with enzymes (trypsin, $1.2 \mathrm{mg} / \mathrm{mL}$ : Sigma, St. Louis, Mo, USA; collagenase D, 1.5-1.8 mg/mL: Roche, Mannhein, BadenWürttemberg, Germany) for 1.5 hours at $34.5^{\circ} \mathrm{C}$. The dissection solution contained the following $(\mathrm{mM}): \mathrm{NaCl} 130, \mathrm{KCl} 5$, $\mathrm{KH}_{2} \mathrm{PO}_{4} 2, \mathrm{CaCl}_{2} 1.5, \mathrm{MgSO}_{4}$ 6, glucose 10 and HEPES 10, $\mathrm{pH} 7.2$. The osmolarity of the solution was $305 \mathrm{mOsm}$. DRGs 

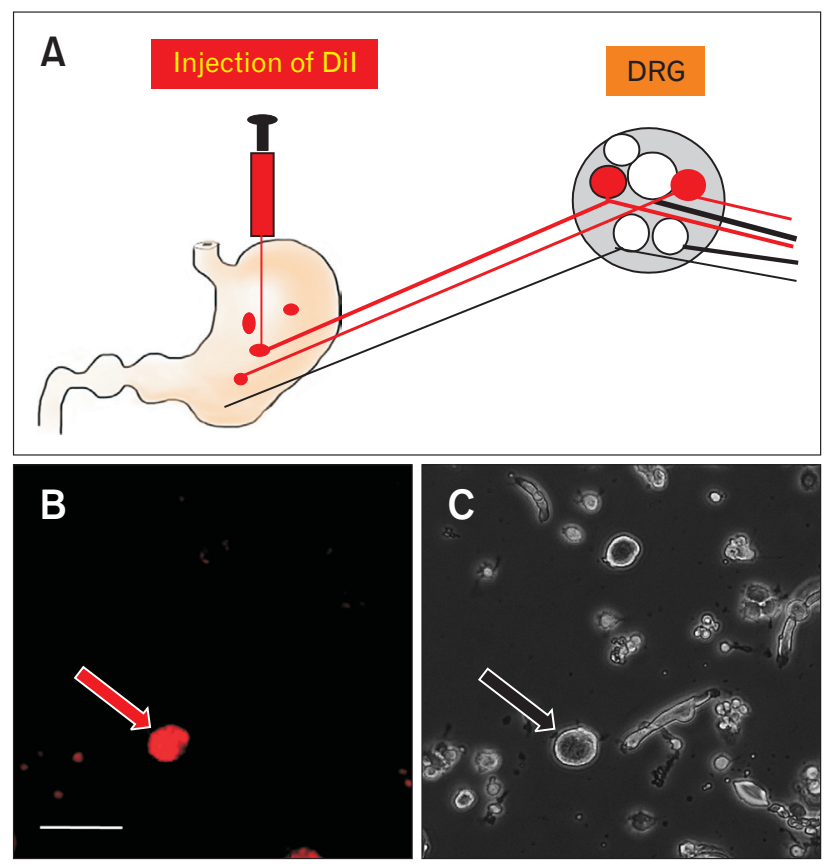

Figure 1. Labeling of gastric projection neurons. (A) Cartoon showing DiI was injected into the stomach wall. (B) Example of a Dillabeled dorsal root ganglion (DRG) cell after acute isolation (arrow). (C) Phase image of the same DRG cell labeled by DiI. Bar $=50 \mu \mathrm{m}$.

were harvested from the enzyme solution, and washed with normal external solution, and then transferred to $2 \mathrm{~mL}$ of the dissecting solution containing DNase $(0.5 \mathrm{mg} / \mathrm{mL})$. Single cell suspension was then harvested by repeated trituration through flame-polished glass pipettes. Cells were put onto acid-cleaned glass coverslips. A coverslip containing the adherent DRG neurons were placed in a recording chamber with a volume of $0.5 \mathrm{~mL}$, which was attached to the stage of an inverted microscope (IX71; Olympus, Tokyo, Japan) equipped for both fluorescence and phase objectives. The external solution contains (mM): $\mathrm{NaCl} 130, \mathrm{KCl} 5, \mathrm{KH}_{2} \mathrm{PO}_{4} 2$, $\mathrm{CaCl}_{2} 2.5, \mathrm{MgCl}_{2}$, glucose 10 and HEPES 10, pH7.2, adjusted by $\mathrm{NaOH}$, osmolarity, 295-300 mOsm. The patch-clamp pipette had a resistance of 3-5 M $\Omega$ when the pipette was filled with the solution, which contained $(\mathrm{mM})$ : potassium gluconate $140, \mathrm{NaCl}$ 10, HEPES 10, glucose 10, BAPTA 5, and $\mathrm{CaCl}_{2}$ 0.01, $\mathrm{pH} 7.25$, adjusted by KOH, osmolarity $295 \mathrm{mOsm}$. Cells labeled by DiI (Fig. $1 \mathrm{~B}$ and $1 \mathrm{C}$ ) were held at $-60 \mathrm{mV}$. Up to $80 \%$ of series resistance was compensated, and potential or current recordings were filtered at $2-5 \mathrm{kHz}$ and sampled at 50 or $100 \mu \mathrm{sec} /$ point. Electrophysiological recordings were performed at room temperature $\left(\sim 22^{\circ} \mathrm{C}\right)$. Data were stored after acquired through HEKA EPC10 (HEKA Instruments, Lambrecht, Germany) and analyzed by Patch Master
Software (HEKA Instruments).

\section{Isolation of Sodium Currents}

To record VGSC currents, previous protocols were used. ${ }^{24}$ In brief, cells were superfused $(2 \mathrm{~mL} / \mathrm{min})$ at room temperature with an external solution, which contains $(\mathrm{mM}): \mathrm{NaCl} 60$, choline chloride $80, \mathrm{CaCl}_{2}$ 0.1, HEPES 10, tetraethylammonium chloride 10 , glucose 10 , and $\mathrm{CdCl}_{2} 0.1, \mathrm{pH} 7.4$ adjusted with tetraethylammonium hydroxide. The osmolarity was adjusted at $\sim 310 \mathrm{mOsm}$. The resistance of the patch electrode was 3-5 $\mathrm{M} \Omega$ when filled with the pipette solution containing $(\mathrm{mM})$ : $\mathrm{CsF} 140, \mathrm{MgCl}_{2} 1$, EGTA 5, Na-GTP 3, glucose 10, and HEPES 10, pH7.2, adjusted with $\mathrm{CsOH}$, osmolarity 285-295 mOsm. The total VGSC currents of DiI labeled cells (Fig. 1B and 1C) were obtained in response to voltage stimulations to different testing potentials from -70 to +50 $\mathrm{mV}$ in $10 \mathrm{mV}$ increments with a duration of $80 \mathrm{msec}$. The sodium peak current was determined as the peak of the transient component of the current at a given voltage. To reduce changes in cell size, the current density $(\mathrm{pA} / \mathrm{pF})$ was calculated by dividing the current amplitude by the cell membrane capacitance.

\section{Implantation of Gastric Distension Balloon and Electromyographic Recordings}

The electromyographic (EMG) recording of the responses of neck muscles to gastric distension (GD) was performed on a total of $14 \mathrm{SD}$ rats as published previously. ${ }^{23,25}$ Briefly, rats were first fasted overnight, and then were deeply anesthetized by intraperitoneal injection of chloral hydrate (200 mg/kg body weight). All surgical procedures were performed under sterile conditions. A balloon of 2.5 $\mathrm{cm}$ in length, made from latex condoms, was attached to a PE-90 catheter. A left lateral epigastric incision $2.5-3.0 \mathrm{~cm}$ long in length was made, and the balloon was put in the stomach through a small hole made at the top of the fundus. The hole was then tightly tied to avoid leakage of stomach contents into the peritoneum. The polyethylene tubing to the gastric balloon was exteriorized at the back of the rat neck and the abdominal skin incisions were closed. Next, sterilized multistranded, Teflon-insulated, 40 gauge stainless steel wires (Cooner Wire, Chatsworth, CA, USA) were implanted in the acromiotrapezius muscles to record EMG activities to gastric distension. Rats were returned to the animal research center for recovery for at least one week. For EMG recording, these rats ( 7 from each group) were first placed in the small Lucite cubicles to allow adaption for at least 30 minutes, and then the EMG responses were recorded to the graded gastric balloon distension by using the Mercury sphygmomanometer under conscious conditions as described 
previously. ${ }^{23}$ The GD protocol was phasic ascending distension (0-20-0-40-0-60-0-80 $\mathrm{mmHg}$ ). The distension duration for each pressure was 20 seconds and breaks for 2 minutes after each distension.

\section{Measurements of Hind Paw Withdrawal Threshold}

The 50\% paw withdrawal threshold (PWT) to a static mechanical stimulus was measured using von Frey filaments as described previously. ${ }^{26-28}$ Normal rats ( $\mathrm{n}=7$ in each group) were placed individually on an elevated iron mesh in a plastic cage to adapt to the testing environment for about 30 minutes. An ascend-
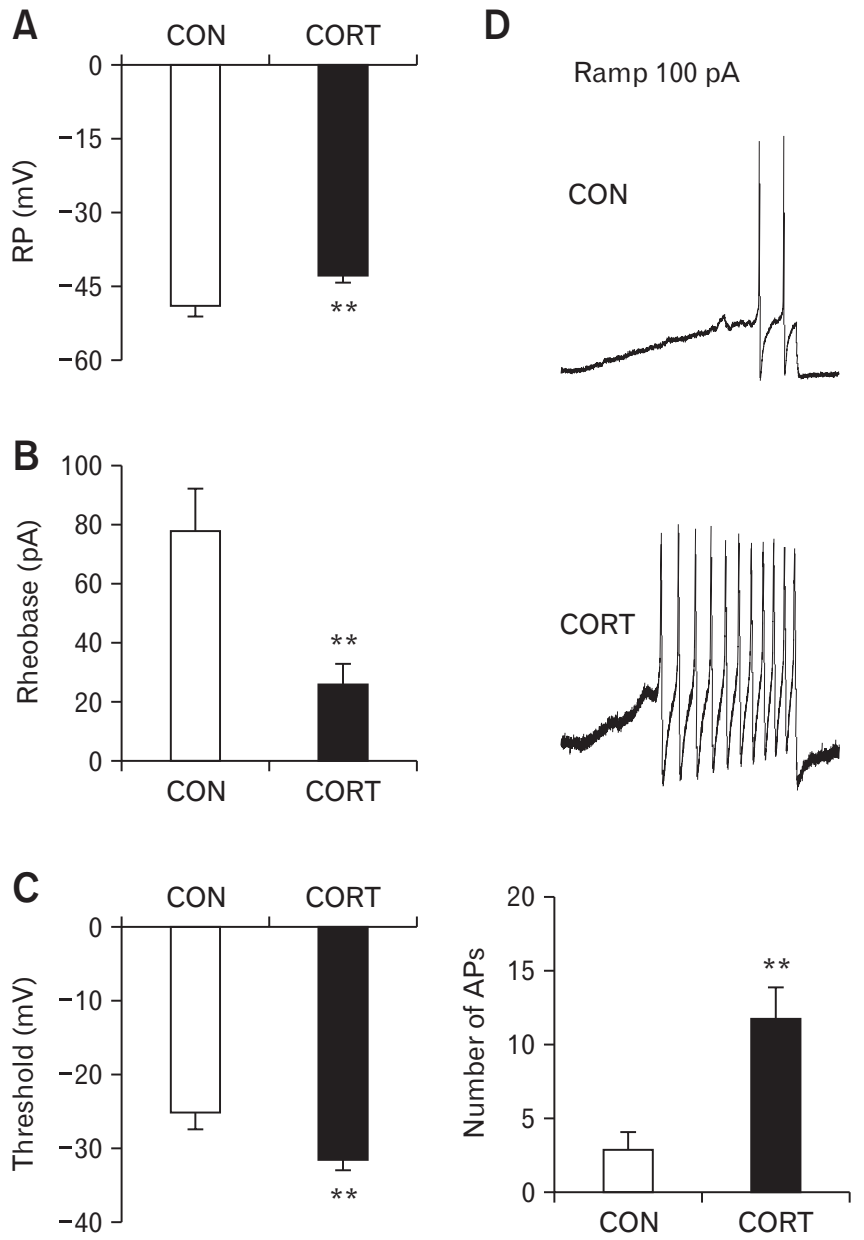

ing series of von Frey hairs (ranging from $0.6 \mathrm{~g}$ to $26.0 \mathrm{~g}$ ) were applied to stimulate the plantar aspect of each hind paw before and after CORT administration. A trial began with the application of the $4.0 \mathrm{~g}$ hair and with $26.0 \mathrm{~g}$ as the cutoff strength of von Frey filaments. A withdrawal of hind paw upon the stimulus was defined as a positive response. If there was a positive response, a filament of a smaller force was then applied. If there was a negative response, a filament of a greater force was then applied. The tactile stimulus producing a $50 \%$ likelihood of withdrawal was determined by the "up-down" calculating method. The mean value was used as the force to produce the withdrawal response.
E

Ramp 300 pA

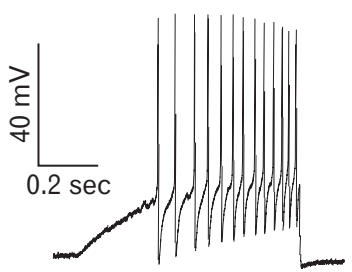

$\mathbf{F}$

Ramp 500 pA

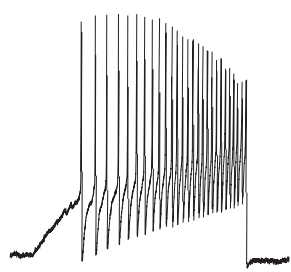

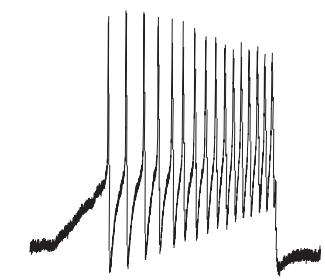
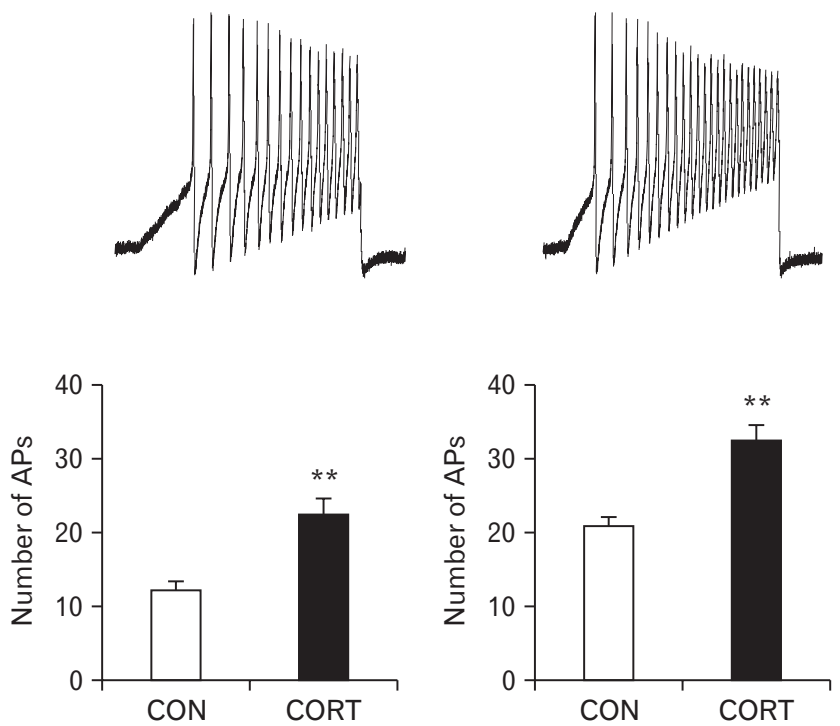

Figure 2. Treatment of corticosterone (CORT) enhanced excitability of dorsal root ganglion (DRG) neurons. (A) CORT application (1 $\mu \mathrm{M}$ for 1 hour) depolarized the resting membrane potential (RP) in DiI-labeled DRG cells ( ${ }^{\star *} P<0.01$, compared with control (CON), Mann-Whitney test). (B) CORT application resulted in a marked reduction of rheobase (**P<0.01, compared with CON, Mann-Whitney test). (C) CORT application significantly hyperpolarized action potential (AP) threshold ( ${ }^{*} P<0.01$, compared with CON, two-sample $t$ test). (D-F) Typical traces of APs evoked by 100,300, and $500 \mathrm{pA}$ ramp current stimulation in the absence (top) or presence of CORT (middle). Bar graphs show the numbers of AP evoked by 100,300 , and $500 \mathrm{pA}$ ramp current stimulation. CORT incubation remarkably increased number of APs $(* * P<0.01$, compared with CON, two-sample $t$ test). 


\section{Reagents}

CORT was obtained from Abcam (ab143597; London, UK). Bisindolylmaleimide I (GF109203X), an antagonist of PKC, was purchased from Aladdin (gl129390; Los Angeles, CA, USA). $\mathrm{H}-89$, an antagonist of protein kinase A (PKA), was purchased from Sigma (B1427; USA). Dimethyl sulfoxide (DMSO) was obtained from Sigma (D8418; Sigma). CORT was initially dissolved in DMSO as a stock solution. The final concentration of DMSO in the extracellular solution was $0.05 \%$. No detectable effect of the vehicle was observed in our experiments.

\section{Data Analysis}

EMG data are presented as area under curve of the integrated EMG after baseline subtraction. All data are expressed as mean \pm SEM in the present study. Statistical analysis was carried out using OriginPro 8 (OriginLab, Hampton, VA, USA) and Matlab (Mathworks, Natick, MA, USA). Normality was checked for all analyses before further analysis. Significance was determined using a two-sample $t$ test for 2 groups. Paired sample Wilcoxon signed rank test, Dunn post hoc test following Friedman ANOVA, and the Mann-Whitney test was done where appropriate. A $P$-value less than 0.05 was considered to be statistically significant.
A
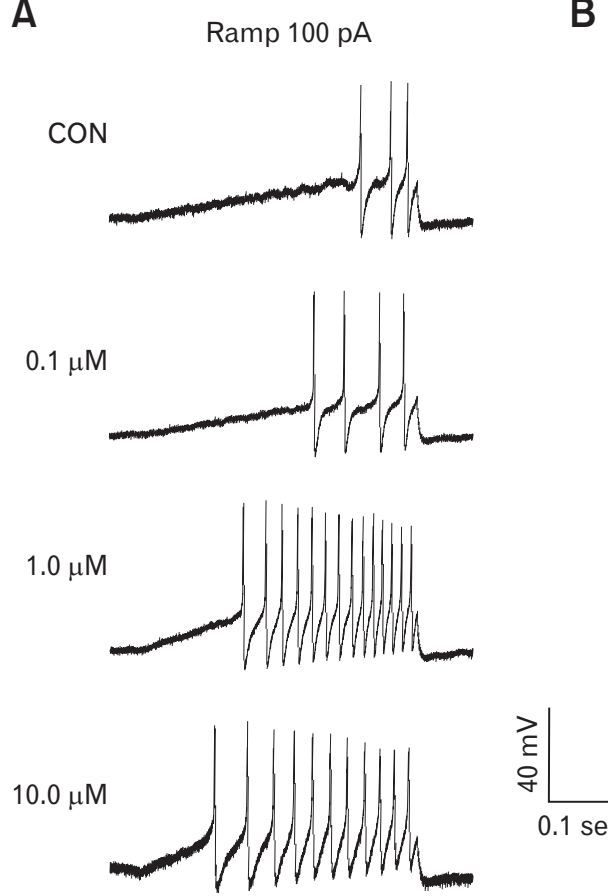

$\underset{0.1 \mathrm{sec}}{\frac{\&}{\delta} \bigsqcup_{0 .}}$
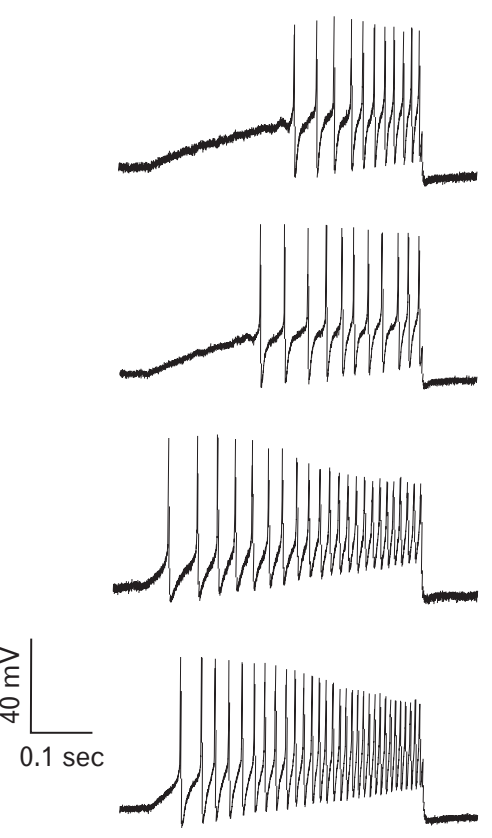
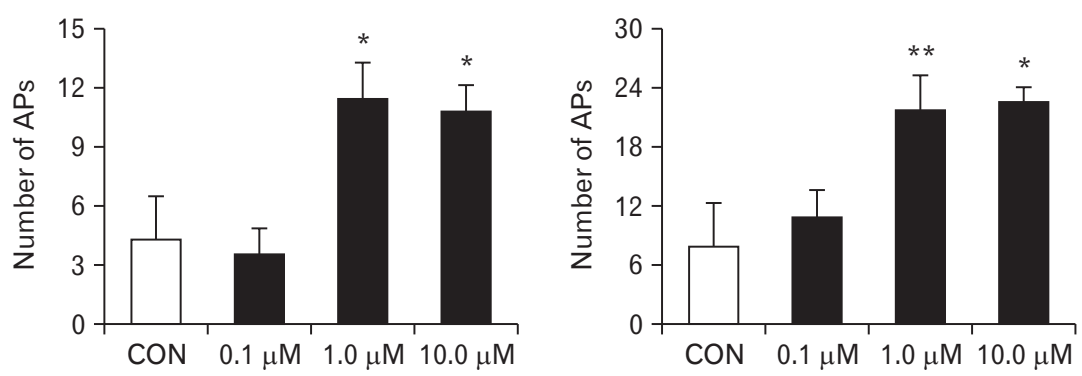

D

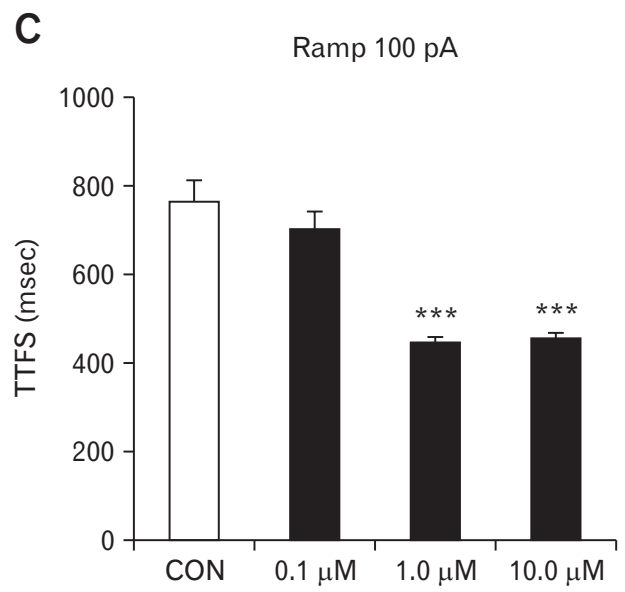

Figure 3. Dose-responses of corticosterone (CORT) incubation. (A, B) Typical traces of action potentials (APs) evoked by $100 \mathrm{pA}$ and $300 \mathrm{pA}$ ramp current stimulation after CORT incubation at different concentrations (top). Bar graphs show a significant increase in numbers of AP evoked by $100 \mathrm{pA}$ and $300 \mathrm{pA}$ ramp current stimulation after CORT application (bottom, ${ }^{*} P<0.05$, ${ }^{* *} P<0.01$, compared with CON, Friedman ANOVA). (C, D) Bar graphs show the time of the first AP evoked by $100 \mathrm{pA}$ and $300 \mathrm{pA}$ ramp current stimulation that were significantly increased after $1 \mu \mathrm{M}$ and $10 \mu \mathrm{M}$ CORT application $(* * * P<0.005$, compared with CON, Friedman ANOVA). 


\section{Results}

\section{Corticosterone Enhances Excitability of Gastric Dorsal Root Ganglion Neurons}

We first investigated the effect of CORT on the activity of gastric projection DRG neurons. To this end, we irrigated DGR neurons with different concentrations of CORT for 1 hour. Gastricspecific DRG (including T7-T10 DRGs) neurons were identified by the fluorescent dye DiI injected into the stomach wall for patchclamp recording (Fig. 1A-C). We measured the passive and active membrane properties of these neurons from control $(\mathrm{CON})$ and CORT-treated cells. The small- and -medium-sized DGR neurons were used in this study, because these neurons are responsible for pain sensation. ${ }^{24,29}$ Under current-clamp conditions, 32 cells were recorded. Resting membrane potentials (RPs) were $-48.9 \pm 0.7$ $\mathrm{mV}(\mathrm{n}=15)$ and $-42.8 \pm 0.4 \mathrm{mV}(\mathrm{n}=17)$ for gastric-specific DRG neurons isolated from CON and CORT-treated groups, respectively. CORT treatment significantly depolarized RPs (Fig. $2 \mathrm{~A}$; ${ }^{*} \mathrm{P}<0.01$, compared with CON, two-sample $t$ test). The rheobase was $77.8 \pm 7.1 \mathrm{pA}(\mathrm{n}=15)$ and $25.9 \pm 4.3 \mathrm{pA}(\mathrm{n}=17)$ for CON and CORT-treated cells, respectively. CORT reduced rheobase (Fig. 2B; ${ }^{* *} \mathrm{P}<0.01$, compared with $\mathrm{CON}$, two-sample $t$ test). The action potential (AP) thresholds were $-25.1 \pm 1.1 \mathrm{mV}$ $(\mathrm{n}=15)$ and $-31.5 \pm 1.3 \mathrm{mV}(\mathrm{n}=17)$ for CON and CORTtreated group, respectively. CORT remarkably hyperpolarized AP threshold (Fig. 2C; ${ }^{* *} P<0.01$, compared with CON, two-sample $t$ test). CORT resulted in a dramatic increase in the numbers of APs evoked by $100 \mathrm{pA}, 300 \mathrm{pA}$, and $500 \mathrm{pA}$ ramp current stimulation (Fig. 2D-F, ${ }^{* *} P<0.01$ compared with $\mathrm{CON}$, two-sample $t$ test). The numbers of APs evoked by $100 \mathrm{pA}$ current ramp stimulation was $2.9 \pm 0.9(\mathrm{n}=15)$ and $11.5 \pm 1.5(\mathrm{n}=17)$ for $\mathrm{CON}$ and CORT-treated cells, respectively. The numbers of APs evoked by $300 \mathrm{pA}$ current ramp was $12.2 \pm 1.2(\mathrm{n}=15)$ and $22.5 \pm$ $2.1(\mathrm{n}=17)$ for CON and CORT-treated cells, respectively. The numbers of APs evoked by $500 \mathrm{pA}$ current ramp was $20.9 \pm 1.9$ $(\mathrm{n}=16)$ and $32.5 \pm 2.8(\mathrm{n}=17)$ for $\mathrm{CON}$ and CORT-treated
A
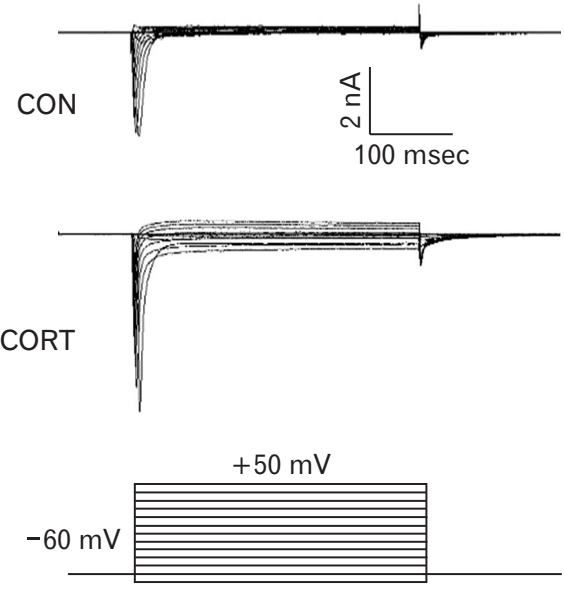

$80 \mathrm{msec}$

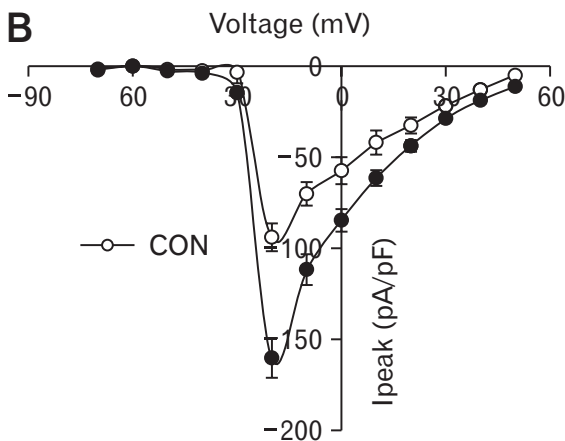

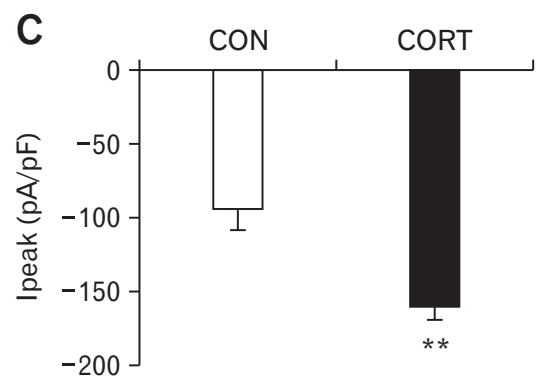

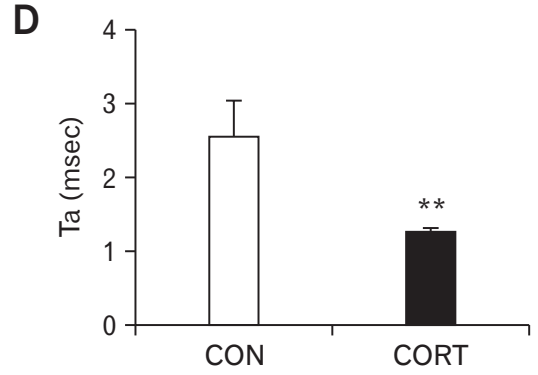

E

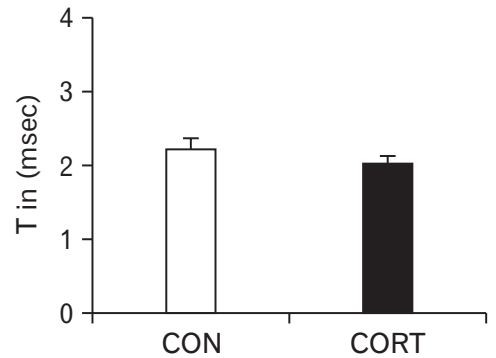

Figure 4. Corticosterone (CORT) enhanced sodium current density. (A) Examples of sodium currents measured from controls (CON; top) and CORTtreated dorsal root ganglion (DRG) neurons (bottom). Membrane potential was held at $-60 \mathrm{mV}$ and voltage steps were from -70 to $+50 \mathrm{mV}$ with $10 \mathrm{mV}$ increments with a duration of $80 \mathrm{msec}$. (B) Current-Voltage $(I-V)$ curves for sodium currents of gastric DRG neurons from CON and CORT groups. (C) Bar graphs show the mean peak sodium current densities. CORT application markedly increased the sodium peak current densities $\left({ }^{*} P<0.01\right.$, compared with CON, Mann-Whitney test). (D) Bar graphs show the mean activation time ( ${ }^{*} P<0.01$, compared with $\mathrm{CON}$, Mann-Whitney test). (E) No significant change was induced by CORT in the half-decay inactivation time $(P>0.05$, compared with $\mathrm{CON}$, Mann-Whitney test). 
cells, respectively. CORT markedly increased the numbers of APs responding to ramp current stimulation. To examine the dose dependency, the cells were divided into 4 groups. The concentration of CORT used was as the followings: $0 \mu \mathrm{M}, 0.1 \mu \mathrm{M}, 1.0 \mu \mathrm{M}$, and $10.0 \mu \mathrm{M}$. Dose-response experiments showed that the enhancing effect was significant at the doses of $1.0 \mu \mathrm{M}$ and $10.0 \mu \mathrm{M}$ (Fig. 3 ; ${ }^{*} P<0.05,{ }^{* *} P<0.01,{ }^{* * *} P<0.005$, compared with 0 $\mu \mathrm{M}$, Friedman ANOVA; $\mathrm{n}=11)$. So, $1 \mu \mathrm{M}$ CORT was used to determine the effect of CORT on sodium currents in the following experiments.

\section{Corticosterone Elevates Voltage-gated Sodium Current Density}

We next examined the change in VGSC current density of DRG neurons before and after CORT treatment. Under voltageclamp conditions, the current-voltage (I-V) relationship was exam- ined (Fig. 4A and 4B). The average peak current density of sodium current obtained from $\mathrm{CON}$ and CORT groups were $93.9 \pm 14.5$ $\mathrm{pA} / \mathrm{pF}(\mathrm{n}=10)$ and $160.24 \pm 8.8 \mathrm{pA} / \mathrm{pF}(\mathrm{n}=12)$, respectively. The average peak current density was significantly increased after CORT treatment (Fig. $4 \mathrm{C} ;{ }^{* *} \mathrm{P}<0.01$, compared with CON, two-sample $t$ test). We then examined the changes in sodium current kinetics after CORT treatment. The current activation time (Ta) between $10 \%$ and $90 \%$ and the half-decay inactivation time $\left(\tau_{\text {in }}\right)$ were measured in peak sodium currents from both CON and CORT groups as described previously. ${ }^{24}$ Ta was $2.5 \pm 0.5 \mathrm{msec}$ (n $=10)$ in control group and $1.2 \pm 0.1 \mathrm{msec}(\mathrm{n}=12)$ in CORTtreated cells. CORT significantly accelerated the activation time (Fig. 4D; ${ }^{* *} \mathrm{P}<0.01$, compared with $\mathrm{CON}$, two-sample $t$ test). However, no significant change in the $\tau_{\text {in }}$ was observed between control and CORT groups (Fig. 4E; CON, $2.2 \pm 0.2 \mathrm{msec}, \mathrm{n}=$ 10; CORT, $1.9 \pm 0.1 \mathrm{msec}, \mathrm{n}=11, P>0.05)$.
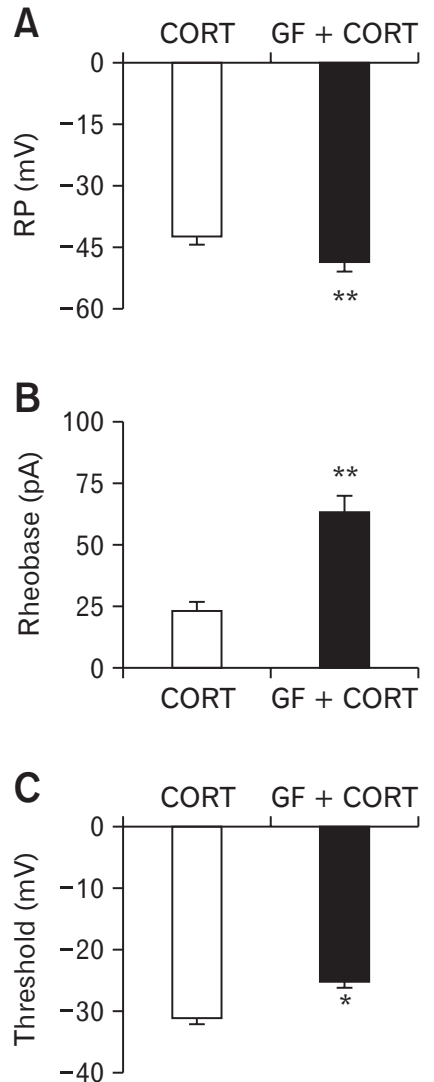

D Ramp 100 pA
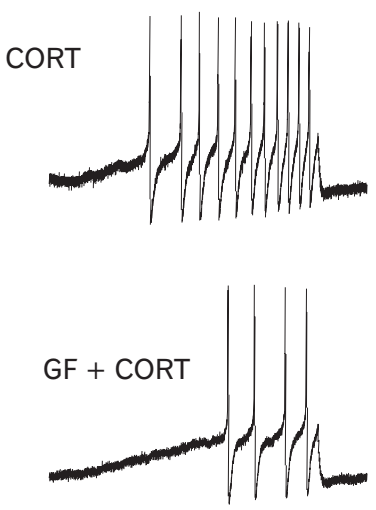

\begin{tabular}{l|l}
$\begin{array}{l}\text { ह } \\
\text { o }\end{array}$ & \\
$0.2 \mathrm{sec}$
\end{tabular}

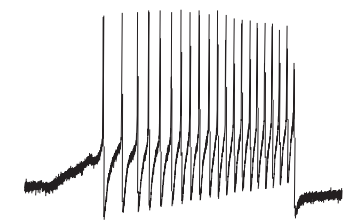

Ramp 300 pA

$\mathbf{F}$

Ramp 500 pA

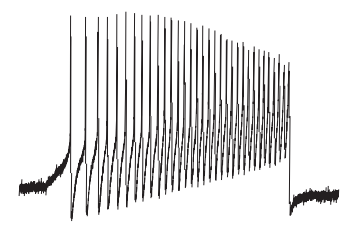

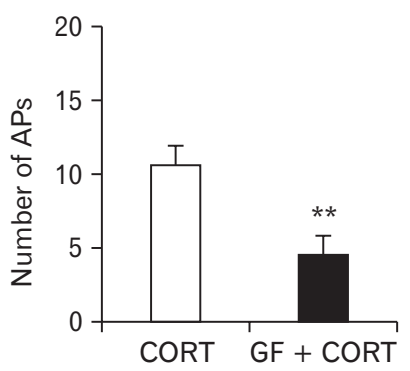
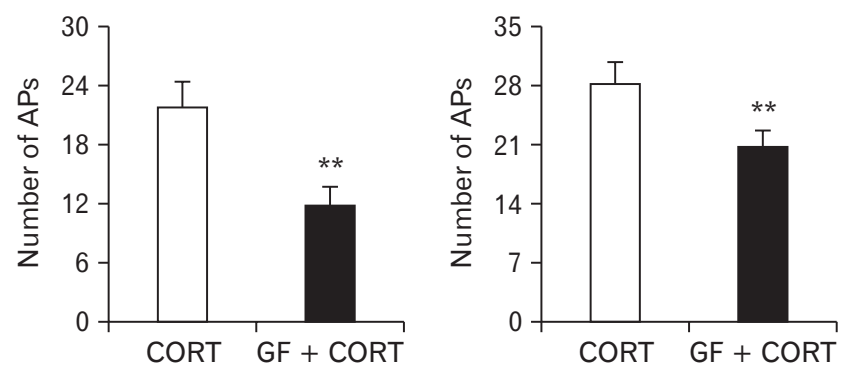

Figure 5. Reversal of corticosterone (CORT)-induced neuronal hyperexcitability by the protein kinase C (PKC) inhibitor GF109203X (GF). (A) GF (1 nM for 15 minutes) application markedly hyperpolarized resting membrane potentials (** $P<0.01$, compared with CORT, Mann-Whitney test). (B) GF application resulted in a marked increase in rheobase ( ${ }^{*} P<0.01$, compared with CORT, two-sample $t$ test). (C) GF application significantly depolarized AP threshold ( ${ }^{* *} P<0.01$, compared with CON, two-sample $t$ test). (D-F) Typical traces of APs evoked by 100,300 , and $500 \mathrm{pA}$ ramp current stimulation (top). Bar graphs show a significant decrease of numbers of AP evoked by 100, 300, and 500 pA ramp current stimulation after GF application (bottom, ${ }^{* *} P<0.01$, compared with CORT, two-sample $t$ test). 


\section{GF109203X Reverses the Corticosterone-induced Hyperexcitability}

We then investigated whether GF109203X, an inhibitor of PKC, ${ }^{30}$ affected the excitability of gastric-specific DGR neurons by CORT. GF109203X at concentration of $3 \mu \mathrm{M}$ was pre-treated with acutely isolated DRG neurons for 15 minutes. Under currentclamp conditions, 28 cells were recorded. RPs were $-43.8 \pm 0.6$ $\mathrm{mV}(\mathrm{n}=15)$ and $-49.1 \pm 0.7 \mathrm{mV}(\mathrm{n}=13)$ for CORT and GF109203X groups, respectively. GF109203X treatment significantly hyperpolarized RPs (Fig. 5A; ${ }^{* *} P<0.01$, compared with CORT, two-sample $t$ test). The rheobase were $23.1 \pm 3.6 \mathrm{pA}$ (n $=15)$ and $63.2 \pm 6.8 \mathrm{pA}(\mathrm{n}=13)$ for CORT and GF109203X group, respectively. GF109203X significantly increased rheobase (Fig. 5B; ${ }^{* *} P<0.01$, compared with CORT, two-sample $t$ test). GF109203 treatment also depolarized the AP threshold (Fig. 5C; CORT, $-31.1 \pm 1.2 \mathrm{mV}, \mathrm{n}=15 ; \mathrm{GF} 109203 \mathrm{X},-25.2 \pm 1.8 \mathrm{mV}$, $\mathrm{n}=13,{ }^{*} \mathrm{P}<0.05$, compared with CORT, two-sample $t$ test). In addition, the numbers of APs evoked by $100 \mathrm{pA}$ current ramp was $10.5 \pm 0.9(\mathrm{n}=15)$ and $4.5 \pm 1.2(\mathrm{n}=13)$ for CORT and GF109203X groups, respectively. The numbers of APs evoked by $300 \mathrm{pA}$ current ramp was $21.7 \pm 2.1(\mathrm{n}=15)$ and $11.9 \pm 1.9(\mathrm{n}$ $=13$ ) for CORT and GF109203X, respectively. The numbers of APs evoked by $500 \mathrm{pA}$ current ramp was $28.5 \pm 2.4(\mathrm{n}=15)$ and $20.7 \pm 2.0(\mathrm{n}=13)$ for CORT and GF109203X groups, respectively. GF109203X treatment remarkably decreased the numbers of APs evoked by 100 pA, 300 pA and 500 pA ramp current stimulation (Fig. 5D-F, ${ }^{* *} P<0.01$, compared with CORT, two-sample $t$ test).

\section{GF109203X Abolishes Corticosterone-induced Potentiation of Sodium Currents}

Since CORT enhanced the sodium current density, we next determined whether CORT enhancement of sodium currents was PKC-dependent. Under voltage-clamp conditions, the I-V relationship was also examined (Fig. 6A and 6B). Pretreatment with GF109203X (3 $\mu \mathrm{M})$ for 15 minutes, CORT no longer increased sodium currents. The average peak current densities obtained from
A
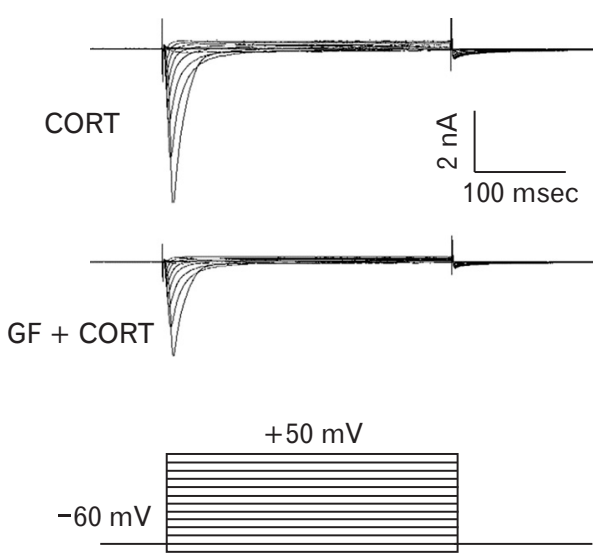

$80 \mathrm{msec}$

B

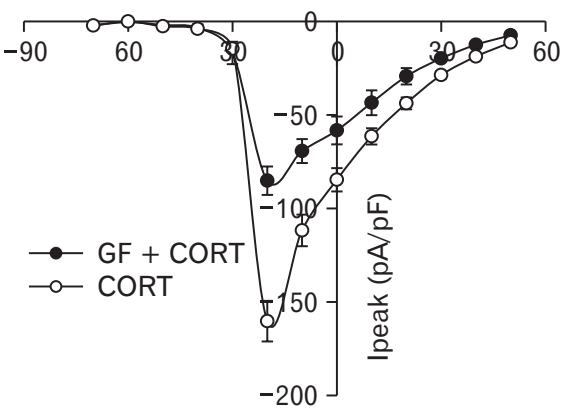

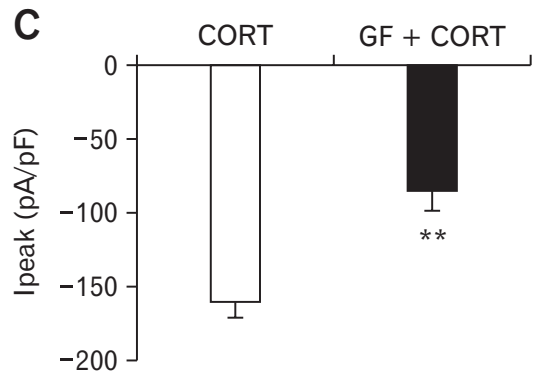

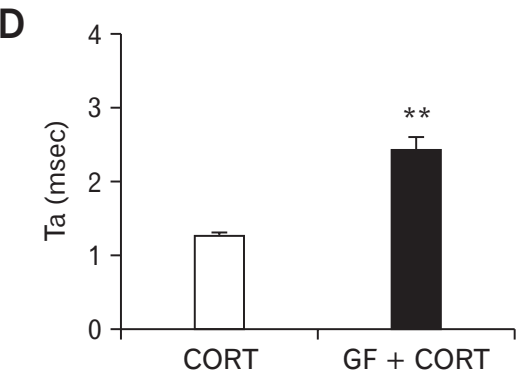

E

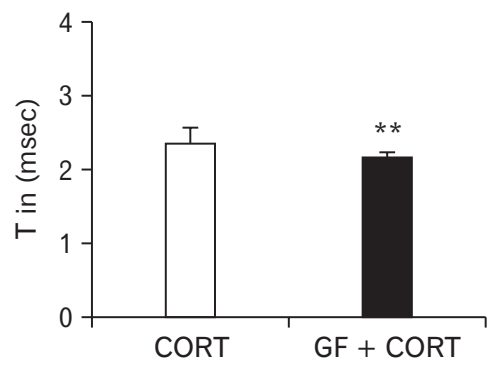

Figure 6. GF109203X (GF) reduced sodium current density. (A) Examples of sodium currents measured from corticosterone (CORT)-treated (top) and $\mathrm{GF}+\mathrm{CORT}$-treated neurons (bottom). Membrane potential was held at -60 $\mathrm{mV}$ and voltage steps were changed from -70 to $+50 \mathrm{mV}$ with $10 \mathrm{mV}$ increments with a duration of $80 \mathrm{msec}$. (B) $I-V$ curves for sodium currents of gastric DRG neurons treated with CORT or GF + CORT. (C) Bar graphs show the mean sodium peak current densities. GF application significantly reduced the peak sodium currents densities $\left({ }^{*} P\right.$ $<0.01$, compared with CORT, MannWhitney test). (D) Bar graphs show the mean activation time $\left({ }^{*} P<0.01\right.$, compared with CORT, Mann-Whitney test). (E) No significant alteration was induced by CORT in the half-decay inactivation time $(P>0.05$, compared with CORT, Mann-Whitney test). 
CORT and GF109203X were $165.3 \pm 6.9 \mathrm{pA} / \mathrm{pF}(\mathrm{n}=12)$ and $85.1 \pm 13.1 \mathrm{pA} / \mathrm{pF}(\mathrm{n}=9)$, respectively. The average peak current density was significantly decreased (Fig. 6C; ${ }^{* *} P<0.01$, compared with CORT, two-sample $t$ test). The Ta was $1.2 \pm 0.1 \mathrm{msec}(\mathrm{n}=$ $10)$ in CORT and $2.4 \pm 0.2 \mathrm{msec}(\mathrm{n}=9)$ in GF109203X, respectively. GF109203X significantly reversed the activation time by CORT (Fig. 6D; ${ }^{*} P<0.01$, compared with CORT, two-sample $t$ test). No significant change in the $\tau_{\text {in }}$ was found between CORT and GF109203X groups $(2.3 \pm 0.1 \mathrm{msec}, \mathrm{n}=9$ in CORT vs 2.1 $\pm 0.2 \mathrm{msc}, \mathrm{n}=10$ in GF109203X + CORT; Fig. 6E).

\section{H-89 Did Not Alter the Corticosterone-induced Enhancement of Sodium Currents}

Some researches indicated that PKA also mediated the sodium currents. ${ }^{31}$ We thus determined whether sodium current is mediated by PKA in the present study. H-89, an antagonist of PKA, at a concentration of $10 \mu \mathrm{M}$ was pretreated for 15 minutes. The $\mathrm{I}-\mathrm{V}$ relationship was also examined (Fig. $7 \mathrm{~A}$ and $7 \mathrm{~B}$ ). The average peak current density obtained from CORT and $\mathrm{H}-89$ treatment was $141.7 \pm 14.0 \mathrm{pA} / \mathrm{pF}(\mathrm{n}=12)$ and $148.9 \pm 14.5 \mathrm{pA} / \mathrm{pF}(\mathrm{n}=$ 9 ), respectively. The average peak current density was not altered by H-89 (Fig. 7C; $P>0.05$, compared with CORT, two-sample $t$ test). The Ta was $2.2 \pm 0.1 \mathrm{msec}(\mathrm{n}=10)$ in CORT and $2.5 \pm$ $0.2 \mathrm{msec}(\mathrm{n}=9)$ in H-89, respectively. H-89 did not significantly affect Ta (Fig; 7D; $P>0.05$, compared with CORT, two-sample $t$ test). No significant change in the $\tau_{\text {in }}$ was found between CORT and H-89 (Fig. 7E; $2.3 \pm 0.3 \mathrm{msec}, \mathrm{n}=9$ in CORT vs $2.1 \pm 0.1$ msec, $\mathrm{n}=10$ in $\mathrm{H}-89$ ).

\section{GF109203X Suppressed Corticosterone-induced Gastric Hypersensitivity}

To record EMGs of the acromiotrapezius muscle responding to GD before and after CORT treatment, implantation of gastric balloon and electrodes were performed 1 week before injection of CORT $(n=14$ rats). One-week after recovery from the surgery, GD-induced painful behaviors were examined 1 hour after CORT injection ( $5.0 \mathrm{mg} / \mathrm{kg}$ body weight, ip). This dose of CORT was used according to our pilot studies and a previous report. ${ }^{32}$ The re-
A
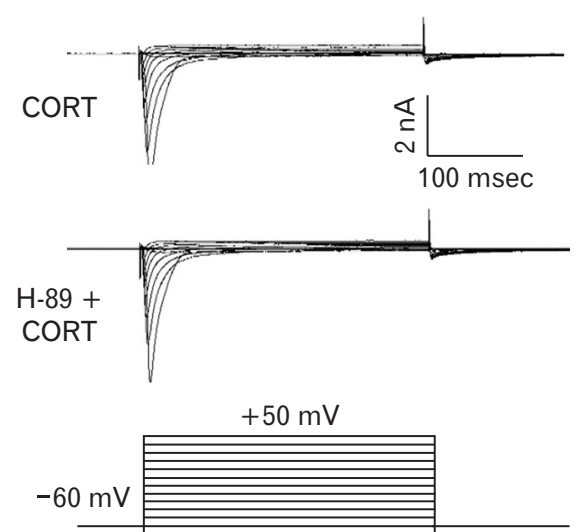

$80 \mathrm{msec}$

B

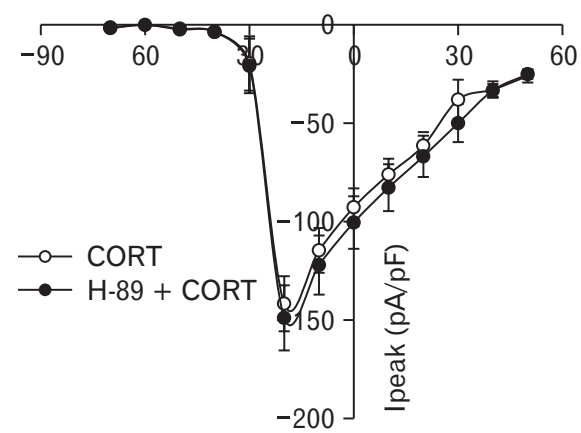

C

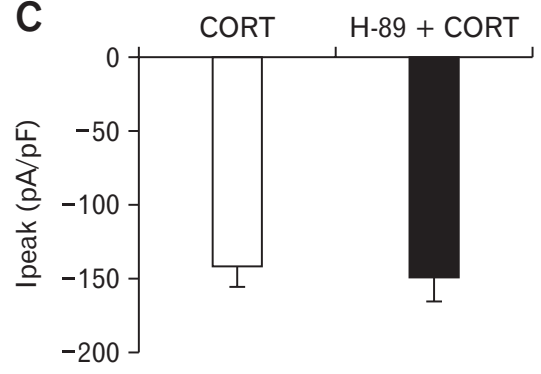

D

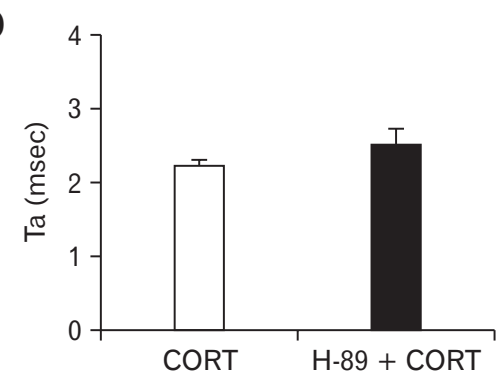

E

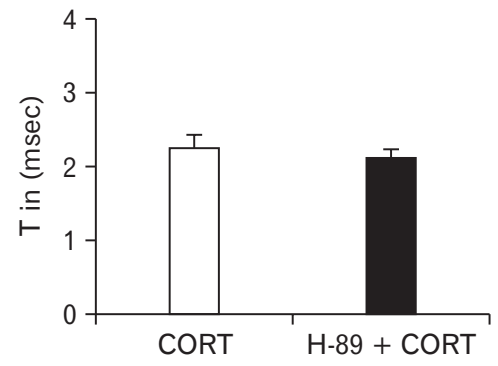

Figure 7. H-89, an antagonist of protein kinase $\mathrm{A}$, did not alter sodium current density. (A) Typical traces of voltagegated sodium currents measured from corticosterone (CORT)-treated (top) and H-89 + CORT-treated DRG neurons (bottom). Membrane potential was held at $-60 \mathrm{mV}$ and voltage steps were altered from -70 to $+50 \mathrm{mV}$ with $10 \mathrm{mV}$ increments with a duration of 80 msec. (B) $I-V$ curves for sodium currents of neurons treated with CORT or H-89 + CORT. (C) Bar graphs show the mean sodium peak current densities. H-89 application did not significantly alter the sodium peak currents densities $(P$ $>0.05$, compared with CORT, MannWhitney test). (D) Bar graphs demonstrate the mean activation time $(P>0.05$, compared with CORT, Mann-Whitney test). (E) No significant change was observed in the half-decay inactivation time by CORT $(P>0.05$, compared with CORT, Mann-Whitney test). 
sults demonstrated that marked effects were observed at distension pressures of 20, 40, 60, and $80 \mathrm{mmHg} 1$ hour after CORT injection (Fig. $8 \mathrm{~A}$ and $8 \mathrm{~B} ; \mathrm{n}=7$ for each group, ${ }^{\star} \mathrm{P}<0.05,{ }^{*} \mathrm{P}<$ 0.01 , compared with pre, paired sample Wilcoxon signed rank test). Gastric hypersensitivity induced by CORT was sustained through the next 1 hour. To determine whether PKC or PKA is involved in the development of gastric hypersensitivity in CORT-treated rats, we examined the effect of GF109203X (PKC inhibitor) and H-89 (PKA antagonist), on EMG amplitude in response to GD. H-89 had no obvious effect on EMG amplitude. However, treatment with GF109203X led to a dramatic reduction in EMG responses at $20-80 \mathrm{mmHg}$ GD pressures (Fig. $8 \mathrm{~A}$ and $8 \mathrm{~B} ; \mathrm{n}=7$ for each group, ${ }^{\#} P<0.05,{ }^{\# \#} P<0.01$, compared with CORT, paired sample Wilcoxon signed rank test). In addition, intraperitoneal injection of CORT did not alter the rat hind PWT in response to von Frey filament stimulation (Fig. 8C; $\mathrm{n}=7$ ).

\section{Discussion}

In the present study, we demonstrated that CORT rapidly enhanced not only the neuronal excitability but also the sodium current density of gastric specific DRG neurons. In addition, systematic injection of CORT induced gastric hypersensitivity in normal rats. These findings suggest that CORT plays an important role in modulating the functions of brain and gut axis. Modulation of ion channels under acute or chronic stress has been increasingly attracting much attention. The influences of stress are elicited at least partly by CORT. The stress hormone CORT has been reported to modulate many ion channels, such as acid-sensing ion channels of cultured hippocampal neurons. ${ }^{33}$ In the present study, we provided direct evidence to show that CORT elevates VGSC currents of DRG neurons innervating the stomach. VGSCs have 9 subunits: $\mathrm{Na}_{\mathrm{v}} 1.1-\mathrm{Na}_{\mathrm{v}} 1.9$ with $4 \beta$ subunits. Among of them, $\mathrm{Na}_{\mathrm{v}} 1.7, \mathrm{Na}_{\mathrm{v}} 1.8$, and $\mathrm{Na}_{\mathrm{v}} 1.9$ are the most abundantly expressed in DRGs and are

A GD pressure $(\mathrm{mmHg})$

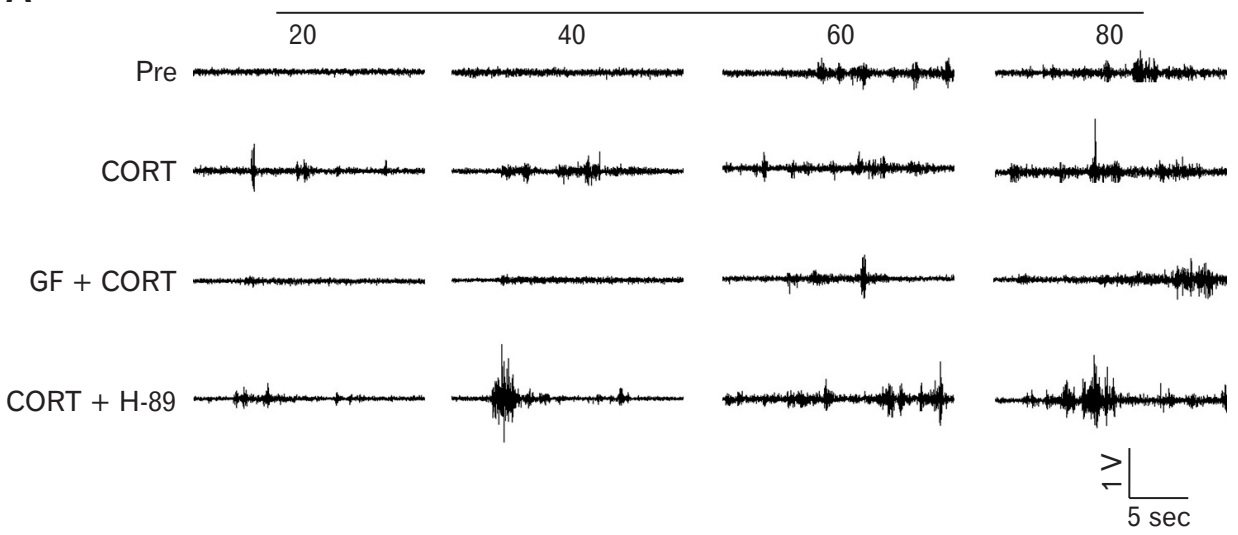

Figure 8. Corticosterone (CORT) produced gastric hypersensitivity. (A) Representative electromyographic (EMG) recordings from normal healthy rats in response to graded gastric distension (GD) 60 minutes after a single injec-

B

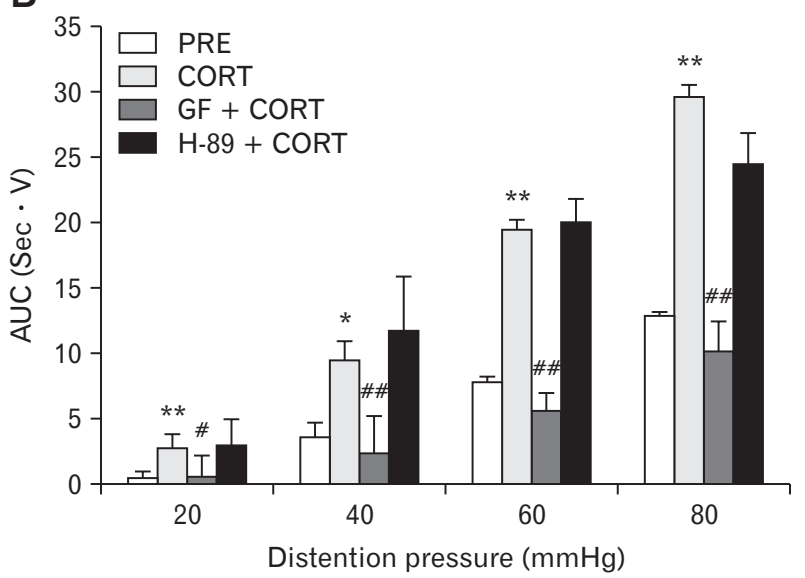

C

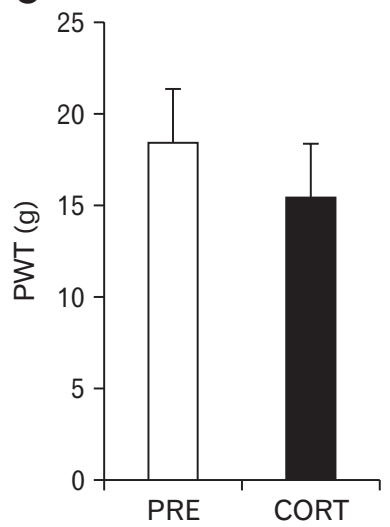
tion of CORT, GF109203X (GF) + CORT or H-89 + CORT. (B) Bar graph shows that CORT intraperitoneal injection produced gastric hypersensitivity $\left({ }^{*} P<0.05,{ }^{*} P<0.01 \mathrm{com}-\right.$ pared with pre-injection (PRE) at the same pressure, paired sample Wilcoxon signed rank test). GF PRE dramatically suppressed EMG amplitude, whereas H-89 had no significant effect EMG $\left({ }^{\#} P<0.05,{ }^{\# \#} P<0.01\right.$ compared with CORT at the pressure, paired sample Wilcoxon signed rank test). (C). CORT injection did not alter the hind paw withdraw threshold (PWT) to von Frey filament stimulation $(\mathrm{n}=14$ rats $)$. 
most closely related to pain in the periphery. ${ }^{34}$ In consistent with previous reports, we provided further evidence to show that VGSCs play an important role in stress and stress hormones response. ${ }^{35}$ Since many drugs in low concentrations have an opposite effect when compared to its high concentrations, ${ }^{36}$ we examined whether enhancement of CORT on excitability of DRG neurons was dosedependent. In our experiments, CORT at $0.1 \mu \mathrm{M}$ had no significant effect on DRG neuronal excitability, but CORT at $1 \mu \mathrm{M}$ significantly enhanced excitability of DRG neurons innervating the stomach, which was the same as CORT at $10 \mu \mathrm{M}$. The active concentration of CORT in the present study is relatively lower than the real blood plasma concentration $(12.15 \pm 0.76 \mu \mathrm{M}, \mathrm{n}=3)$. This difference may be because the DRG neurons were isolated in vitro. To the best of our knowledge, this is the first report that CORT plays a rapid effect on DRG neurons innervating the stomach of healthy rats.

The mechanism by which CORT modulates neuronal excitability and sodium channel function has yet to be investigated. In addition to genomic pathways, CORT is thought to activate ion channels in central neurons through non-genomic pathways. ${ }^{17,33}$ An earlier study showed that incubation of epinephrine $(5 \mathrm{nM})$ or CORT $(1 \mu \mathrm{M})$ overnight sensitized the DRG neurons, ${ }^{15}$ indicating that stress hormone-induced sensitization of DRG neurons might be through the enhanced transcription of ion channels. In the present study, however, this is least likely the case because we exposed DRG neurons with CORT for only 1 hour and the time was not long enough to affect the expression of proteins according to previous reports. ${ }^{33,36}$ Therefore, the rapid CORT effects may occur independently of the regulation of the gene expression of sodium channels in the present study. Previous studies suggest that CORT acts by signaling directly to GRs on DRG neurons or, alternatively, by enhancing levels of other pro-nociceptive mediators after immune activation in the colon. ${ }^{11,37}$

A better understanding of the molecular mechanisms underlying stress hormone-induced alterations in neuronal excitability and sodium channel function is crucial for the development of novel beneficial therapeutic strategies. Several earlier studies have showed that protein kinase can modulate function of sodium channel by phosphorylating targeting motif. ${ }^{38}$ Since CORT signaling pathway can activate PKC and PKA signaling pathways, ${ }^{36}$ so we speculated that the CORT effects on sodium currents might be mediated by PKC and/or PKA. Although others kinase-signaling pathways cannot be excluded, we showed that CORT-induced effects are dependent of PKC but independent of PKA in gastric specific DRG neurons. There are several reasons that may explain the differences in PKA and PKC effects. The concentration of these two inhibitors may not be a major reason for the differences in PKC and PKA effect since the doses were selected according to previous reports ${ }^{33,39}$ and our pilot studies. We speculate that CORT-induced rapid effects may be tissue-, cell type-, and ion channel-specific, as others have reported that CORT-induced rapid effect on ATP currents is PKA dependent. ${ }^{40}$ However, this needs to be further investigated. How PKC enhances sodium channel function remains largely unknown. PKC usually regulates the transcription-translation mechanism. Since the incubation time was short (ie, 1 hour), we hypothesize that the transcriptional mechanism might not be involved in the present study. The possible mechanisms included but not excluded the phosphorylation of sodium channels and enhanced trafficking of sodium channels from the cytoplasm to the cell surface membrane. ${ }^{20}$ In the present study, although CORT did not alter $\tau_{\text {in }}$, it significantly reduced Ta of sodium currents. This result suggests that CORT-induced enhancement of sodium current density may not because of aggregation of sodium channel on cell membrane, but at least in part because of changes in channel kinetics. Since the Ta was shorter after CORT treatment, it is therefore reasonable to hypothesize that all sodium channels are open or have a trend to open at the same time. Increase in ion channel conductance was another possible mechanism, but this needs to be further investigated in the future.

It is worthy knowing that systemic administration of CORT produced gastric hypersensitivity while this did not alter the hind PWT of the normal rats. Although at the present time, we cannot provide much more evidence to distinguish possible mechanisms underlying the differentiation of visceral hypersensitivity and somatic pain sensation by CORT, this result strongly suggested that the effect induced by systematic use of CORT is visceral pain specific and it is not a non-specific or toxic effect. It is also reasonable since the visceral organs are particularly vulnerable to stress. This implies that the acute stress causes visceral responses more often and earlier than somatic responses. Consistent with previous studies that stress led to colonic hypersensitivity ${ }^{41,42}$ and functional dyspepsia-like gastric hypersensitivity in rats, ${ }^{7}$ which was most likely mediated by stress hormones such as CORT and epinephrine, we demonstrated for the first time that CORT injection induced gastric hypersensitivity in normal rats. However, the detailed mechanisms of systematic application CORT are not well understood. It is, however, very tempting to hypothesize that CORT in vivo application might share the same mechanism in producing gastric hypersensitivity as it effects neurons in vitro. This CORT-induced effect may explain the stress-induced epigastric pain syndrome or postprandial distress 
syndrome.

In summary, we have provided a novel nociceptive signaling pathway of CORT in gastric DRG neurons. CORT incubation induces neuronal hyperexcitability and potentates the sodium channel function, which is likely mediated by PKC but not PKA. Most importantly, systemic use of CORT leads to development of gastric hypersensitivity of healthy rats. These findings imply that stressinduced increase in CORT levels might potentiate sodium channel activities and shed light on the mechanisms of gastric hypersensitivity in patients with FD induced by advert stress conditions. Our studies might also provide beneficial therapeutic strategies for the treatment of FD.

Financial support: This work was supported by grants from the National Key Research and Development Program of China (Grant No. 2016YFC1302200), National Natural Science Foundation of China (Grant No.81230024 and 81471137), and Priority Academic Program Development of Jiangsu Higher Education Institutions of China.

\section{Conflicts of interest: None.}

Author contributions: Meng Li researched and analyzed data, prepared figures, and wrote the manuscript; Lu Xue researched and analyzed data, and prepared the figures; Hong-Yan Zhu researched data and prepared the figures; Hongjun Wang researched and analyzed data; Xue Xu researched data; Ping-An Zhang researched data; Geping Wu researched and analyzed data; and Guang-Yin Xu designed and supervised the experiments, and edited the manuscript. All authors discussed the results and approved the manuscript.

\section{References}

1. Ford AC, Marwaha A, Sood R, Moayyedi P. Global prevalence of, and risk factors for, uninvestigated dyspepsia: a meta-analysis. Gut 2015;64:1049-1057.

2. Talley NJ, Walker MM, Holtmann G. Functional dyspepsia. Curr Opin Gastroenterol 2016;32:467-473.

3. Stanghellini V, Chan FK, Hasler WL, et al. Gastroduodenal disorders. Gastroenterology 2016;150:1380-1392.

4. Keto Y, Hirata T, Takemoto Y, Yamano M, Yokoyama T. Influence of gastric acid on gastric emptying and gastric distension-induced pain response in rats--effects of famotidine and mosapride. Neurogastroenterol Motil 2012;24:147-153, e88.

5. Stanghellini V, Tosetti C, Paternico A, et al. Risk indicators of delayed gastric emptying of solids in patients with functional dyspepsia. Gastroenterology 1996;110:1036-1042.

6. Ehlert U, Nater UM, Bohmelt A. High and low unstimulated salivary cortisol levels correspond to different symptoms of functional gastrointestinal disorders. J Psychosom Res 2005;59:7-10.

7. Winston JH, Sarna SK. Developmental origins of functional dyspepsialike gastric hypersensitivity in rats. Gastroenterology 2013;144:570-579, e3.

8. Wouters MM, Boeckxstaens GE. Is there a causal link between psychological disorders and functional gastrointestinal disorders? Expert Rev Gastroenterol Hepatol 2016;10:5-8.

9. Moussaoui N, Jacobs JP, Larauche M, et al. Chronic early-life stress in rat pups alters sasal corticosterone, intestinal permeability, and fecal microbiota at weaning: influence of sex. J Neurogastroenterol Motil 2017;23:135-143.

10. Yang L, Shi LJ, Tang B, et al. Opposite sex contact and isolation: a novel depression/anxiety model. Neurosci Bull 2016;32:92-98.

11. Hong S, Zheng G, Wiley JW. Epigenetic regulation of genes that modulate chronic stress-induced visceral pain in the peripheral nervous system. Gastroenterology 2015;148:148-157, e7.

12. Habib KE, Gold PW, Chrousos GP. Neuroendocrinology of stress. Endocrinol Metab Clin North Am 2001;30:695-728, vii-viii.

13. Gareau MG, Jury J, Yang PC, MacQueen G, Perdue MH. Neonatal maternal separation causes colonic dysfunction in rat pups including impaired host resistance. Pediatr Res 2006;59:83-88.

14. Zhou Y, Li RJ, Li M, et al. Overexpression of GRK6 attenuates neuropathic pain via suppression of CXCR2 in rat dorsal root ganglion. Mol Pain 2016;12:1-13.

15. Ochoa-Cortes F, Guerrero-Alba R, Valdez-Morales EE, et al. Chronic stress mediators act synergistically on colonic nociceptive mouse dorsal root ganglia neurons to increase excitability. Neurogastroenterol Motil 2014;26:334-345.

16. Sakurai A, Fukushima Y. [Basic information on medical genetics for internists (2).] Nihon Naika Gakkai Zasshi 2008;97:3093-3100. [Japanese]

17. Takahashi T, Kimoto T, Tanabe N, Hattori TA, Yasumatsu N, Kawato S. Corticosterone acutely prolonged $\mathrm{N}$-methyl-D-aspartate receptor-mediated $\mathrm{Ca}^{2+}$ elevation in cultured rat hippocampal neurons. J Neurochem 2002;83:1441-1451.

18. Komatsuzaki Y, Hatanaka Y, Murakami G, et al. Corticosterone induces rapid spinogenesis via synaptic glucocorticoid receptors and kinase networks in hippocampus. PLoS One 2012;7:e34124.

19. Strickland IT, Martindale JC, Woodhams PL, Reeve AJ, Chessell IP, McQueen DS. Changes in the expression of $\mathrm{Na}_{v} 1.7, \mathrm{Na}_{v} 1.8$ and $\mathrm{Na}_{v} 1.9$ in a distinct population of dorsal root ganglia innervating the rat knee joint in a model of chronic inflammatory joint pain. Eur J Pain 2008;12:564572.

20. Yan J, Zou K, Liu X, et al. Hyperexcitability and sensitization of sodium channels of dorsal root ganglion neurons in a rat model of lumber disc herniation. Eur Spine J 2016;25:177-185.

21. Pan HL, Liu BL, Lin W, Zhang YQ. Modulation of $\mathrm{Na}_{v} 1.8$ by lysophosphatidic acid in the induction of bone cancer pain. Neurosci Bull 
2016;32:445-454.

22. Lee SP, Sung IK, Kim JH, Lee SY, Park HS, Shim CS. The effect of emotional stress and depression on the prevalence of digestive diseases. J Neurogastroenterol Motil 2015;21:273-282.

23. Zhang $\mathrm{HH}, \mathrm{Hu}$ J, Zhou YL, et al. Promoted interaction of nuclear factor-KB with demethylated cystathionine- $\beta$-synthetase gene contributes to gastric hypersensitivity in diabetic rats. J Neurosci 2013;33:9028-9038.

24. Hu S, Xiao Y, Zhu L, et al. Neonatal maternal deprivation sensitizes voltage-gated sodium channel currents in colon-specific dorsal root ganglion neurons in rats. Am J Physiol Gastrointest Liver Physiol 2013;304:G311-G321.

25. Liu LS, Shenoy M, Pasricha PJ. The analgesic effects of the GABAB receptor agonist, baclofen, in a rodent model of functional dyspepsia. Neurogastroenterol Motil 2011;23:356-361, e160-e161.

26. Chaplan SR, Bach FW, Pogrel JW, Chung JM, Yaksh TL. Quantitative assessment of tactile allodynia in the rat paw. J Neurosci Methods 1994;53:55-63.

27. Qi F, Zhou Y, Xiao Y, et al. Promoter demethylation of cystathionine$\beta$-synthetase gene contributes to inflammatory pain in rats. Pain 2013;154:34-45.

28. Zhou YL, Jiang GQ, Wei J, et al. Enhanced binding capability of nuclear factor-KB with demethylated $\mathrm{P} 2 \mathrm{X} 3$ receptor gene contributes to cancer pain in rats. Pain 2015;156:1892-1905.

29. Hunt SP, Mantyh PW. The molecular dynamics of pain control. Nat Rev Neurosci 2001;2:83-91.

30. Wan X, Lu Y, Chen X, et al. Bimodal voltage dependence of TRPA1: mutations of a key pore helix residue reveal strong intrinsic voltagedependent inactivation. Pflugers Arch 2014;466:1273-1287.

31. Einholm AP, Nielsen HN, Holm R, Toustrup-Jensen MS, Vilsen B. Importance of a potential protein kinase a phosphorylation site of $\mathrm{Na}^{+}$, $\mathrm{K}^{+}$-ATPase and its interaction network for $\mathrm{Na}^{+}$binding. J Biol Chem 2016;291:10934-10947.

32. Alexander JK, DeVries AC, Kigerl KA, Dahlman JM, Popovich PG. Stress exacerbates neuropathic pain via glucocorticoid and NMDA receptor activation. Brain Behav Immun 2009;23:851-860.
33. Xiong Z, Liu Y, Hu L, Ma B, Ai Y, Xiong C. A rapid facilitation of acid-sensing ion channels current by corticosterone in cultured hippocampal neurons. Neurochem Res 2013;38:1446-1453.

34. Dib-Hajj SD, Binshtok AM, Cummins TR, Jarvis MF, Samad T, Zimmermann K. Voltage-gated sodium channels in pain states: role in pathophysiology and targets for treatment. Brain Res Rev 2009;60:65-83.

35. Strickland MJ, Riehle-Colarusso TJ, Jacobs JP, et al. The importance of nomenclature for congenital cardiac disease: implications for research and evaluation. Cardiol Young 2008;18(suppl 2):92-100.

36. Yoshiya M, Komatsuzaki Y, Hojo Y, et al. Corticosterone rapidly increases thorns of CA3 neurons via synaptic/extranuclear glucocorticoid receptor in rat hippocampus. Front Neural Circuits 2013;7:191.

37. Myers B, Greenwood-Van Meerveld B. Differential involvement of amygdala corticosteroid receptors in visceral hyperalgesia following acute or repeated stress. Am J Physiol Gastrointest Liver Physiol 2012;302:G260-G266.

38. Poulsen H, Nissen P, Mouritsen OG, Khandelia H. Protein kinase A (PKA) phosphorylation of $\mathrm{Na}^{+} / \mathrm{K}^{+}$-ATPase opens intracellular Cterminal water pathway leading to third $\mathrm{Na}^{+}$-binding site in molecular dynamics simulations. J Biol Chem 2012;287:15959-15965.

39. Fernández-Millán E, Martín MA, Goya L, et al. Glucagon-like peptide-1 improves beta-cell antioxidant capacity via extracellular regulated kinases pathway and Nrf2 translocation. Free Radic Biol Med 2016;95:16-26.

40. Liu XH, Zeng JW, Zhao YD, Chen PH, Xiao Z, Ruan HZ. Rapid inhibition of ATP-induced currents by corticosterone in rat dorsal root ganglion neurons. Pharmacology 2008;82:164-170.

41. Xiao Y, Chen X, Zhang PA, Xu Q, Zheng H, Xu GY. TRPV1-mediated presynaptic transmission in basolateral amygdala contributes to visceral hypersensitivity in adult rats with neonatal maternal deprivation. Sci Rep 2016;6:29026.

42. Zhang PA, Xu Q, Xue L, et al. Neonatal maternal deprivation enhances presynaptic $\mathrm{P} 2 \mathrm{X} 7$ receptor transmission in insular cortex in an adult rat model of visceral hypersensitivity. CNS Neurosci Ther 2017;23:145-154. 